\title{
Research on the Cultivation Mechanism of Boutique Project of College Students' Work
}

\author{
Chao Wang ${ }^{1, a}$ and Junzheng Wang ${ }^{2, b^{*}}$ \\ ${ }^{1}$ Xincheng Street 2888, Jilin Agricultural University, Changchun, Jilin Province 130118, PR China \\ a29251275@qq.com, b595845966@qq.com \\ *The corresponding author
}

Keywords: Student work; Project; Construction; Mechanism

\begin{abstract}
In this era of rapid change, quality education has become a trend. It takes ten years to grow trees, but a hundred to rear people. According to the growth stage of the students, target to carry out the relevant boutique projects. In the activities of education and guidance work is conducive to the growth of students. Quality project construction is very important. This paper discusses the boutique project construction of several mechanisms.
\end{abstract}

\section{Connotation of Students' Work}

Student work is to deal with student life, learning and other related work. The main contents include: the assessment of scholarship, organize students to participate in various activities, help students with various procedures, the issuance of student loans, and student parent communication, etc.

\section{The Connotation and Characteristics of Boutique Project of Students' Work}

The Connotation of Boutique Project of Students' Work. The students' work quality project refers to the idea of taking students as the foundation and developing students' work as the principle, students' growth and success as the goal, covering students quality education, ideological education, community activities, help life etc., have a significant impact on improving education quality.

Characteristics of Boutique Project of Students' Work. The students' work quality project has the characteristics of recognition, uniqueness, era, operability and demonstration.

\section{The Necessity of the Construction of Boutique Product of Students' Work}

Requirements of Quality Education. In this era of rapid change, quality education is particularly important. To enhance the students' comprehensive quality has become the primary task of education. The development of the students' work quality project can cultivate students' self-confidence, self-reliance, unity, sense of responsibility, perseverance, initiative, innovation and so on. The development of the students' work quality projects can effectively improve the quality of students and cultivate the special talents for the society.

The Development of Colleges and Universities. It takes ten years to grow trees, but a hundred to rear people. Developing the country through science and education. Major colleges and universities in the school conditions, scientific research equipment and other hard power and the strength of teachers, scientific research and other soft power to strive for first-class. However, whether we can cultivate a man of qualities, is an important indicator to measure the level of development of colleges and universities. The implementation of the students' work quality project plays an indispensable role in the cultivation of students' comprehensive quality.

Students' Own Growth Requirements. According to the growth stage of the students, targeted to carry out the relevant quality projects. Do a good job in education and guidance. 


\section{The Principle of Quality Project Construction}

Consistent with the Development of the School. Each university has its own development direction and unique advantages. The construction of the project should conform to the characteristics and development direction of the school. In the construction of quality projects, we need to rely on the platform provided by the school and the environment. Therefore,the project that not match with the development of the school, will encounter difficulties in the construction, destined not to become a boutique project, will be eliminated.

Consistent with the Direction of Development of Student Work. The construction of quality project is one of the important contents of student work. Therefore, in the construction of the project, we should pay attention to consistent with the interests of the development of student work.

In Line with the Direction of the Development of Students' Personal Qualities. The object of school education is students. The main object of the student work is the student. Therefore, the quality of the project should be based on the development of students' personal quality as the direction of development, the students learn more useful knowledge, exercise capacity, improve the overall quality of the individual as the ultimate goal.

Complementary Advantages. The quality of the project and other students work to be interrelated, complementary advantages, to show the student work style and charm.

Have Short and Long Term Goal. The construction of student work is a long-term process. In the process of construction, we must first establish a long-term goal, a big forward direction. Then, the long term goal is split into many short-term goals, namely, short-term tasks within a semester. Achieve short-term goals by achieving a short term goal. In the construction, we need to down-to-earth, and make adjustments to the unreasonable place, step by step to achieve the goal. In the construction process, should not be too impatient, so as to avoid unnecessary mistakes.

Continuous Innovation. The cultivation of the students' work is a long-term task. In the process of construction, the need the guidance of project management, education and other related theory, and constantly improve.

\section{Designing Quality Items Should Be Paid Attention to the Following Five Aspects.}

According to the Subject of the School, Design Boutique Products. In many projects, relying on the students to learn the professional design of the project is most likely to be made boutique items. The learning process of students in university is a continuous and gradual process. With the further study of students, activities continue to develop. Reward students to encourage students to actively participate in activities. Related professional course teacher can also participate in them, answering questions for students, guide students to complete the activity. Through communication between teachers and students, to create a harmonious relationship between teachers and students, enhance the feelings of teachers and students. In this process, the students are guided to make students interested in learning and activities. Training characteristic talents for the society.

Relying on School Resources, Unified Organization Activities. The cultivation of students' activities can not be separated from the unified organization of the school and the education department. With the help of the relevant departments and actively cooperate, in order to quickly form a competitive boutique projects.

Expand Publicity Through the Network. In today's era, the network has become an indispensable part of teachers and students work and study. Network media is very convenient, has its unique advantages. The use of a good network of new media, can achieve a multiplier effect. Through micro-blog, WetChat, QQ and other network platform for publicity, in a short period of time to allow students to understand the project, expand the influence of the project to facilitate the smooth development of the project.

Keep Pace with the Times and Innovate. Only innovation can develop. College students always think actively and they have the courage to accept new things. Therefore, the design of students' work quality projects also need to keep up with the trend of the times. Only by keeping pace with the new thinking of the students, the project can stimulate the interest of the students, so 
that they can get the praise from the students, and then they can truly become a quality project.

Part of the Activities Can be Close to the Livelihood of the People As Far As Possible. College students in the school have a shortcoming that is the lack of social experience. However, students will graduate one day, and go into the sociaty. Therefore, some activities close to the livelihood of the people, so that students stand in the perspective of society to think, you can try to make up for their own shortcomings, so that students grow faster.

\section{The Construction of Students' Work Quality Project Is Divided into the Following Three Aspects}

Allow Students to Approve Projects. The most important thing in the cultivation of students' work is to cultivate students' sense of identity. Especially in the early stage of project construction, students are not very understanding of the project. Through posters, WeChat, QQ, campus radio and other means of publicity, so that students understand the project, to stimulate students' interest in the project. The student cadre is the student's elite, is the teacher's right-hand man. In the early stage of the project construction, we should give full play to the exemplary role of the student cadres, so that they can lead the students to participate in the project. Let the outstanding students encourage students to actively participate in. In this process, let the students gradually love the project, identity project. So as to lay the foundation for the smooth construction of the project.

Teaching Staffa Counselor. The counselor plays an important role in the construction of the students' work. At the first day in college, the first person that students contact is counselor. Students encounter problems in life, the first thought is to contact counselors. Most of the student work is carried out under the guidance of the instructor. In the process of work and study, counselors and students to establish a good relationship between teachers and students, and gradually developed into the most trusted friend. The instructor has carried on the ideological and political education to the student, helps the student to establish the correct outlook on life, the values, the world outlook, leads the student to complete the social practice and so on the important task. Counselors have a profound impact on students. Therefore, counselors play an indispensable role in the construction of students' work.

To strengthen the construction of counselor team. A counselor need to face many students. These students come from different families, have different backgrounds, have different ideas and independent personality. If you want to face the different students to make quality projects, you need to continue to learn the relevant professional knowledge, improve their overall quality, enhance their personality charm. In order to go into the student groups, to understand the students' psychology, so as to build the support of students' favorite boutique items.

Cultivate the awareness of the construction of the excellent project.China's colleges and universities in the scientific research and other aspects of strength and strive to first-class. However, the work of college counselors is very trivial, repetitive, routine work more. Counselors often lack the sense of innovation, it is difficult to build quality projects.

To improve the professional quality of counselors. In the process of project construction, it is necessary for counselors to have self-confidence, responsibility, innovation ability and organization ability. Counselors should use the knowledge of Ideological and moral education and the relevant theories of Marx's sinicization. There will be many challenges in the process of cultivation and construction. The need for counselors in the face of problems, with a calm, analysis of the problem, the ability to carry out psychological intervention.

Other Tutors. Ideological and political teachers should stand on the theoretical level, the project to explain and publicize. In this way, the theory will be linked to the actual, the theory is no longer boring, but also to mobilize the enthusiasm of the students, encourage students to take the initiative to participate in the project.

Some of the top quality items are related to the students' professional knowledge. This requires the close cooperation of professional teachers and patient guidance. Teachers should help counselors to do a good job in the publicity of the project, so that students learn more about the project, so that students actively participate in the project to. Teachers in the same field can form a 
team to conduct exchanges. It is helpful to guide the teachers to make a comprehensive consideration on the organizational process and safeguard measures. Stimulate the ability of teachers to develop the potential to make the project better. At the same time, professional teachers should further improve their professional quality, so as to ensure the smooth development of the project.

Policy System. At present, although the major colleges and universities in cultivating students work fine project construction work has made some achievements, but there are still many problems. The project selection is not careful, evaluation standard is not perfect, resource allocation is not reasonable, the reward is not in place. This requires the establishment of relevant policy system, so as to ensure the smooth construction of the project.

Building leadership mechanism. School leaders should actively cultivate the awareness of the construction of quality projects, but also into action. The school must have a long-term plan to the project construction. As far as possible the project and teaching, scientific research and other professional knowledge together. To analyze the feasibility of the project, design the project implementation plan, etc.. And constantly improve the quality of the project to better serve students. As far as possible to provide human resources, money, activities, facilities and other aspects of support for the project. At the same time, good coordination among the departments of the mission, in close coordination, division of labor, improve efficiency.

Construct guarantee mechanism. Improve the relevant system and promote the work step by step. For the project, set up a special student organization. Students supervise each other, help each other, help the teacher to complete the project, the students themselves are also in the work to improve the overall quality.

Establish incentive mechanism. Outstanding teachers and students in the construction of the project to give a certain material and spiritual rewards. If you have the opportunity, you can promote outstanding deeds through the media, and encourage all teachers and students to participate actively.

To establish the evaluation system of counselor work. Cultivation can be added to the assessment of counselors. So that the instructor is more actively involved in the project construction work.

\section{Conclusion}

Campus culture can influence the behavior of students in the subtle. Through the cultivation of high-quality projects, let the students a correct outlook on life, world outlook and values.

In the course of activities, students can get out of the book, improve their overall quality, to become useful. This paper discusses the construction of College Students' work quality project construction of several mechanisms, in order to strive to create the boutique project, and effectively improve the quality of students, to create a unique brand.

\section{Acknowledgements}

This article is the research work of the Chinese Society of Higher Education Student Work Research Branch 2016 years of college students work research topic "college counselor specialization construction research" (subject approval number: LX2016Y013) research results.

\section{References}

[1] K Zhang, Research on the cultivation model of College Counselors' work.

[2] Q Zhu, Research on the cultivation and construction of College Counselors' excellent projects.

[3] X Fang, on the cultivation of College Students' activities.

[4] J.B Xiang, Research on the cultivation mechanism of Higher Vocational College Students' work. 
[5] P Chen, Research on the path of brand creation of the excellent work of counselors under the perspective of individual development.

[6] C.W Yu, Exploration and practice of promoting the specialization level of Counselors Based on the perspective of quality project construction.

[7] J Lin, Research on the construction and application of comprehensive evaluation model of students' work in Higher Vocational Colleges.

[8] M.M Zhang, Research on the construction of College Counselors' work.

[9] Z.Y Tan, On the cultivation of high quality campus culture in Higher Vocational Colleges.

[10]C Xie, Study on the mechanism of College Students' quality development based on College Students' Associations. 